\title{
La lectura apocalíptica de René Girard: catástrofe y esperanza
}

\author{
René Girard's Apocalyptic Reading: \\ Catastrophe and Hope
}

\author{
Anabel Muñoz Trejo \\ Universidad Nacional Autónoma de México \\ anabel.mutre@gmail.com \\ orcid.org/oooo-ooo1-5124-8602
}

Resumen: El presente artículo propone recurrir a la teoría mimética de René Girard, para abordar el tema de la violencia y su escalada a los extremos, desde una perspectiva no instrumental. Dicha teoría localiza el origen de la violencia en la naturaleza mimética de los deseos adquisitivos y devela, como su principal antídoto histórico, el sacrificio de víctimas expiatorias. En ese sentido, expone a la violencia, y a sus distintas manifestaciones, como el principal motor de la historia de la humanidad. De forma central, este artículo aborda la posibilidad de desmontar dicha violencia, a través de la lectura girardiana del Apocalipsis como el rostro de la crisis actual y como un llamado de esperanza. Ambas vertientes derivadas de un mismo episodio: La Revelación cristiana que, tras desmontar el aparato sacrificial y dejar a los hombres sin protección sagrada, presentaría a la víctima inocente por antonomasia - Cristo- como el único modelo a imitar a fin de frenar la maquinaria de muerte.

Palabras clave: apocalipsis, sacrificio, violencia, deseo mimético, chivos expiatorios, cristianismo, esperanza, revelación

Abstract: This paper proposes to draw on René Girard's "mimetic theory" to understand the phenomenon of violence and its escalation to extremes, from a non-instrumental perspective. This theory locates the origin of violence in the mimetic nature of acquisitive desires and it reveals, as its main historical antidote, the sacrifice of scapegoats. Accordingly, it suggests that violence and its various manifestations are a prime driving force in human history. Mainly, this paper addresses the possibility of dismantling this violence through Girard's reading of the Apocalypse as the face of the current crisis and a call for hope. Both strands originate from the same episode: Christian Revelation, after dismantling the sacrificial apparatus and leaving men without sacred 
protection, presented the innocent victim par excellence - Christ - as the only role model able to stop the machinery of death.

Keywords: $\quad$ apocalypse, sacrifice, violence, mimetic desire, scapegoat, Christianity, hope, Revelation

Recibido: $\quad 2$ de junio de 2019

Aceptado: 18 de febrero de 2020

La redención no es un premio a la existencia sino el último recurso de un ser humano para el que, en las palabras de Kafka, «la propia frente... hace que el camino se le extravíe».

Walter Benjamin

Durante los últimos siglos, el mundo ha enfrentado un recrudecimiento del conflicto entre los hombres y entre las naciones. Lejos de la reconciliación universal anunciada por Hegel, la oposición de los contrarios se ha radicalizado.

Hoy puede constatarse lo que, en la primera mitad del siglo XIX, Carl von Clausewitz describía como una "escalada a los extremos" propia de la guerra; una serie de contraofensivas en las que las pasiones de los individuos involucrados ocupan un lugar central:

Cuán lejos estaríamos de la verdad si atribuyéramos la guerra entre hombres civilizados a actos puramente racionales de sus gobiernos, y si la concibiéramos como libre siempre de todo apasionamiento...

$\mathrm{Si}$ la guerra es un acto de fuerza, las emociones están necesariamente involucradas en ella. Si las emociones no dan origen a la guerra, esta ejerce, sin embargo, acción mayor o menor sobre ellas, y el grado de reacción depende, no del estado de civilización, sino de la importancia y la duración de los intereses hostiles (Clausewitz 2015: 10, 11).

A propósito de tal reflexión, René Girard afirma - Clausewitz en los extremos (2010) - que lo que el militar prusiano intuía como la esencia de la guerra anunciaba la reciprocidad violenta que hoy invade todas las relaciones humanas y que amenaza con colapsar al mundo tal y como lo conocemos.

A decir de Girard, en Vom Kriege — su obra inacabada-, Clausewitz observa el imperio de una ley mimética que rebasaba todos los marcos de la 
política y de la racionalidad militar. Las pasiones se habían convertido en el principio rector de las guerras napoleónicas y revolucionarias. Los sentimientos de hostilidad o de pertenencia fortalecían el primado de la defensa por sobre el ataque. Dado que nadie tenía la sensación de agredir, se aseguró un triunfo cada vez mayor de la violencia. La razón política permaneció impotente para determinar los objetivos y los límites del enfrentamiento.

El principio de guerra radicaba, pues, en corresponder a la violencia del adversario con una violencia igual o superior. "De este modo, uno fuerza la mano del adversario y cada cual impulsa al otro a la adopción de medidas extremas cuyo único límite es el de la resistencia que le oponga el contrario" (Clausewitz 2015: 10). La alternancia infinita de acciones recíprocas borraba las diferencias reales entre los oponentes y los llevaba a radicalizarse en las oposiciones más baladíes.

Clausewitz advierte que esa tendencia reconfiguraría el carácter de la guerra tradicional y produciría un nuevo sentido de la violencia: esta, no solo se intensificaría con el paso del tiempo, también involucraría y movilizaría cada vez a más gente, hasta que sus alcances se volvieran globales.

En una palabra, hasta las naciones más civilizadas pueden inflamarse con pasión en el odio recíproco. [...] Repetimos por lo tanto nuestra afirmación: la guerra es un acto de violencia y no hay límite para la aplicación de dicha violencia. Cada uno de los adversarios fuerza la mano del otro y esto redunda en acciones recíprocas que teóricamente llegarán a los extremos. Esta es la primera acción recíproca que se nos presenta y el primer extremo (Girard 2010: 27).

A principios del siglo XIX, la "guerra total" ya era una realidad. Para Enzo Traverso, con ella se inauguraría la fase más aterradora y destructiva de la modernidad. El ideal del progreso material fue desmentido por "una masacre serializada y tecnificada cuyo fruto era la muerte ya no glorificada, sino serializada: una muerte 'sin atributos' una muerte masiva anónima” (Traverso 2015: 10). Mientras que, en el siglo pasado, ya Adorno y Horkheimer describirían hasta qué punto la barbarie se había deslizado en las estructuras más íntimas de la sociedad. Como nunca, podía observarse a la violencia funcionar como el eje articulador de la acción organizada de los hombres.

Para Girard, el gran acierto de Clausewitz consistió en percibir, hace casi dos siglos, el comienzo de esa escalada acelerada hacia la catástrofe; la fórmula apocalíptica vinculada a la rivalidad. Clausewitz fue un avisador del fuego. 
Sin embargo, sostiene Girard, aquel imperio que el teórico militar reconoció no fue otra cosa que la ley que rige los lazos humanos desde el principio de los tiempos, pues, como el propio Clausewitz precisó, la guerra no es más que un duelo a gran escala. Esa ley es la de la naturaleza mimética ${ }^{1}$ y conflictiva de nuestros deseos. Y aunque ciertamente sus efectos se han agudizado en los últimos siglos, se trata de un elemento constitutivo de toda formación social. Tal lectura constituye la tesis central de la teoría mimética que Girard desarrolla a lo largo de cinco décadas.

La teoría girardiana afirma que, a la par de una mímesis positiva que históricamente ha garantizado la transmisión cultural y la convivencia entre los miembros de un grupo, existe una mímesis negativa vinculada a los deseos. Dicha mímesis constituye el origen de la violencia humana, pero también el fundamento de la hominización.

Si la estructura psíquica y la estructura social revelan que el aprendizaje, el habla, la técnica, etc., tienen su raíz en la figura de la otredad, no hay nada que debiera hacernos concebir al deseo como una entidad absolutamente autónoma. El deseo solo puede observarse como esa proyección interminable de las necesidades constitutivas del ser en el otro, como un eslabón más de la larga cadena mimética que nos constituye como humanos. No hay nada más detrás de él que la imitación de otro deseo, deseo por el mismo objeto y, por lo tanto, una fuente inagotable de conflictos y rivalidades (Girard 2006a: 54).

Esta tesis contradice el ideal moderno de la autonomía: nuestros deseos no nos pertenecen. ${ }^{2}$ Son siempre la imitación de un deseo ajeno y, como tal, conducen a la elección de los mismos objetos elegidos por nuestros modelos. Hablamos de una mímesis de apropiación. De manera predecible, la igualdad de los deseos y la imposibilidad de satisfacción que ello implica produce relaciones de rivalidad y violencia entre las partes involucradas.

1 A pesar de que, en repetidas ocasiones, Girard recurre indistintamente a los términos imitación y mímesis, considera necesario distinguirlos. El primero, considera, implica un mayor grado de conciencia sobre sus formas operativas, mientras que las causas y los efectos de la segunda son prácticamente desconocidos.

2 La teoría mimética refuta ese vínculo lineal que en el psicoanálisis freudiano describe al deseo. En su lugar, propone una figura triangular, con los vértices ocupados por un sujeto (imitador), un modelo y un objeto de deseo. En dicha estructura, el objeto solo tiene un papel secundario; el modelo, en cambio, ocupa la posición primigenia y vinculante; es quien, a través de sus propios deseos, indica al sujeto lo que debe desear. 
El sujeto, convencido de la autonomía de sus deseos, percibe al otro - su modelo- como el obstáculo a derribar para su realización personal; mientras que él es percibido de la misma forma por aquel. Bajo el influjo mimético, la violencia inter-pares se intensifica y se reproduce en toda la sociedad, hasta el punto en que cualquier relación parece insostenible. Se despliega así una crisis mimética.

Ningún contrato social, ningún aparato jurídico y ninguna institución coercitiva resultan suficientes para contener la violencia y para restaurar el orden. Todo parece destinado a la ruina. No obstante, la propia naturaleza mimética producirá el remedio a esa crisis social, a través de la figura de un enemigo común. En lo que se define como una mímesis del antagonista.

La violencia generalizada y multifocal es contenida por otra violencia, de tipo unánime, contra una víctima arbitraria: un chivo expiatorio al que se responsabiliza de la crisis y al que se cree preciso sacrificar para purificar el conjunto. Los múltiples disensos tienden a unificarse en torno a la persecución y a la eliminación de dicha figura.

Para que el mecanismo sacrificial funcione, es necesario que todos acaben "por convencerse de que un pequeño número de individuos, o incluso uno solo, puede llegar pese a su debilidad relativa a ser extremadamente nocivo para el conjunto de la sociedad" (Girard 2005: 88). La rectitud de la causa propia solo derivará de la certeza con la que la colectividad crea oponerse a la culpabilidad y a la "maldad" del otro. Esta suerte de transferencia es lo que garantiza que la violencia unánime cumpla con su principal objetivo: la expiación.

Dicho de otro modo, solo la mentira y el desconocimiento permiten que la destrucción de la víctima pueda asumirse como una operación de justicia y no como un asesinato o un acto de violencia pura; que la violencia adquiera un carácter unánime y restaurador de las relaciones sociales.

Girard señala:

Una sola víctima puede sustituir a todas las víctimas potenciales, a todos los hermanos enemigos que cada cual se esfuerza en expulsar, esto es, en todos los hombres sin excepción, en el interior de la comunidad. El indicio más ridículo, la más ínfima presunción, se comunicará de unos a otros a una velocidad vertiginosa y se convertirá casi instantáneamente en una prueba irrefutable. La convicción tiene un efecto acumulativo y cada cual deduce la suya de la de los demás bajo el efecto de una mímesis casi instantánea. La firme creencia de todos no exige otra comprobación que la unanimidad irresistible de su propia sinrazón (Girard 2005: 87-88). 
Lo cierto es que tanto la unanimidad como el desconocimiento que sostienen al mecanismo sacrificial deben comprenderse a la luz de una misma fuente explicativa: la tendencia humana a plantear la violencia como un fenómeno exterior. Si la persecución unánime resulta algo tan atractivo para los individuos, es porque en el encuentro del otro-culpable cada uno de ellos puede expulsar la verdad de su propia violencia mimética.

Hallándose dentro, la víctima es perniciosa, un enemigo; estando fuera, se vuelve benéfica. Más aún, se le diviniza, pues es a ella a quien se atribuye la salvación de la comunidad. "El retorno de la paz parece confirmar la culpabilidad de la víctima. Basta comprender que la inversión de la relación real entre la víctima y la comunidad se perpetúa en la resolución de la crisis, para comprender también por qué esa víctima es tenida por sagrada" (Girard 1982: 38). Por ese motivo, Girard afirma que el sacrificio debe ser reconocido como la fuente de lo religioso — del latín religio, religare: 'religar', 'vincular', 'atar'-y este, a su vez, como la matriz de la sociedad. El sacrificio, nos dice, "es la institución primordial de la cultura humana" (Girard 2012: 75).

En sus palabras:

Lo religioso es todo lo que se observa y todo lo que no se observa del mecanismo sacrificial; son sus efectos próximos y lejanos, los comportamientos que suscita, las circunstancias que lo favorecen o entorpecen. Con la instantaneidad del rayo, el mecanismo sacrificial libera a todos los hombres sin excepción, salvo quizá a la propia víctima que, debido a eso, puede convertirse en un ídolo tras su desaparición. Nadie puede dominar el fenómeno, nadie puede manipularlo. Tiene todos los caracteres de una intervención sobrenatural. Todo en él sugiere un poder que trasciende la miserable humanidad. Constituye el prototipo de toda epifanía sagrada. No es difícil concebir que los hombres religiosos sean devotos en cuerpo y alma de este misterio que les salva (Girard 1989: 94).

El sacrificio representa el núcleo de lo sagrado. A decir del autor, solo en el sacrificio la violencia y lo sagrado muestran su unidad: un papel autónomo y fundador, que se distancia por completo de su interpretación instrumental.

Como se dijo, los hombres son incapaces de reconocer su propia violencia y responsabilidad en la crisis mimética y, más bien se la atribuyen a fuerzas exteriores e indómitas que los acosan y exigen de ellos tales ejecuciones. Lo sagrado aparece, entonces, como esa exterioridad capaz de contener la verdad y el velo de la violencia humana; así como para conceder a los hombres el beneficio de seguir existiendo y procrastinar su autodestrucción. 
Mientras que Freud interpretó esta transición como la expresión de un estado neurótico individual, la teoría mimética sostiene que se debe explicar como el resultado de una ilusión colectiva propiciada por la propia mímesis. "La mímesis es así simultáneamente causa de la crisis y motor de la resolución" (Girard 2010: 52). Expulsión y comunión como expresiones de un continuum.

Luego de una serie de revisiones antropológicas, Girard concluye que, en las sociedades antiguas, el mecanismo sacrificial fue lo que permitió a las comunidades zanjar sus violencias intestinas. ${ }^{3}$ Ya a través del rito o del establecimiento de una de serie de tabúes y jerarquías derivadas de este.

Después de un primer sacrificio, el acto debió reproducirse ritualmente buscando concluir nuevos ciclos de violencia. Miles de víctimas habrían sido inmoladas en momentos de crisis, las mismas a las que después se adoró y se convirtió en un centro de significaciones para todo el grupo. 4

De ahí que, según Girard, el politeísmo deba ser comprendido como la transfiguración de todas esas víctimas en figuras protectoras. No comprender y asimilar esta ambivalencia hace que los individuos se convenzan de que su reconciliación debe ser atribuida a la naturaleza excepcional de la víctima. 5

La figura excluida diferencia todo lo que la crisis sometió al terror de lo idéntico. "No hay ninguna significación que no se esboce en ella y que no pa-

$3 \mathrm{Al}$ respecto, Girard reconoce que la práctica sacrificial es algo que no necesariamente se presenta en todos los ritos pues, dice, no se trata de un determinismo; no obstante, más tarde volverá a su tono tajante y añadirá que todo parece indicar que las colectividades que han carecido de esta resolución seguramente desaparecieron (Girard 2006b: 64).

4 Aparentemente nos encontramos con una interpretación idéntica a la hecha por Freud en Tótem y tabú en relación con el "padre vigía”; sin embargo, existen notables diferencias entre ambas propuestas teóricas. Girard acusa a la tesis freudiana de tener una alta superfluidad e incongruencia. Su crítica se dirige en dos sentidos fundamentales: por un lado, el que dicha teoría presente al sacrificio como un acto único, fundacional y "prehistórico" — casi fantasioso- y, por otro, el que pierda de vista la existencia y las funciones cotidianas de las víctimas. En la teoría mimética, el sacrificio es algo real y en constante ejercicio; ciertamente, un acto conmemorativo, pero que va más allá de eso y que exige el despliegue de una violencia efectiva en cada una de sus representaciones. Respondiendo a Freud, Girard considera que el papel fundador del sacrificio es algo tan cierto que su práctica se puede constatar en distintas culturas que, geográficamente, nunca pudieron haberse influido entre sí.

5 Esta cualidad es la que lo convierte en un homo sacer - figura estudiada de forma magistral por Giorgio Agamben - una imagen límite del orden social que se sustrae, por igual, al derecho divino y al derecho humano. En todos los sentidos, se trata de una figura excepcional. 
rezca al mismo tiempo trascendida por ella [...] se constituye entonces como significante universal" (Girard 1982: 116). Solo a partir de la víctima se puede distinguir entre un dentro y un afuera, entre la comunidad y lo sagrado. La víctima es la única que puede dar cuenta del nexo inexorable entre el desorden mimético y la fundación de un nuevo orden.

Las observaciones antropológicas sugieren al autor que, a medida que las prácticas rituales se disgregaron, la lógica sacrificial cimentó las instituciones. Afirma Girard:

Las instituciones culturales deben interpretarse todas como transformaciones del sacrificio, al final de una evolución que las especializa poco a poco en los ámbitos de actividad más rodeados de sacrificios, por ser los más susceptibles de engendrar conflictos, como el funeral, el matrimonio, la iniciación, la comida, la educación, el poder político, etc. (Girard 2012: 76).

De la repetición surge el aprendizaje y del aprendizaje el diseño de conductas e instituciones que mantienen alejados los conflictos. Por lo que el Leviatán hobbesiano solo puede ser entendido como un sucedáneo del mecanismo que aquí observamos. Orden ritual y orden institucional se erigen sobre el mismo fundamento explicativo.

Caifás, el sumo pontífice de los Evangelios, enunciaría su formulación más exacta en la condena a Cristo: "es mejor que perezca un hombre y no que perezca la nación [...] Caifás encarna la política bajo su forma superior y no la inferior. Caifás es el mejor de los políticos" (Girard 2002a: 151). La violencia sacrificial aparece, entonces, como el único garante de la vida en común.

Los hombres, incapaces de ponerse de acuerdo sobre el objeto de sus deseos, siempre logran hacerlo a expensas de un enemigo común, de la destrucción de una víctima. Tal como Pierre Clastres apunta, en Investigaciones en antropología política, "indivisión sociológica y parcelamiento externo" son las dos caras de una única realidad (Clastres 1987: 214).

Puede notarse que, en este sentido, la teoría girardiana muestra más cercanía con el planteamiento schmittiano - que reconoce lo político como aquello que reconduce todas sus acciones y motivos, a partir de la distinción amigo-enemigo (Schmitt 2014: 59) - que con aquellos que lo inscriben en un estado de armonía natural. Para Girard, la política solo se realiza en la reciprocidad violenta y en la conclusión sacrificial que esta demanda. 
Esto significa que la política va a la zaga de la violencia y no al revés. Desde los ritos antiguos hasta la guerra de Irak, la violencia sacrificial se revela como el verdadero motor de la historia.

A decir de Girard, solo un suceso habría sido capaz de perturbar dicha marcha histórica: la revelación cristiana. ${ }^{6}$ Los textos cristianos representan la principal fuente de saber sacrificial pues, además de evidenciar el proceso victimario que sostiene el orden desde la creación del mundo, develan a la violencia humana en todo su esplendor. Esta irrupción es registrada como el principio de la modernidad. 7

La revelación cristiana se presenta históricamente en dos fases: "hay primeramente una transición del mito a la Biblia, en la que dios se desvictimiza y las víctimas se desdivinizan [...] y viene después la plena revelación del Evangelio. Dios participa entonces de la experiencia de la víctima, pero esta vez deliberadamente, para liberar al hombre de su violencia" (Girard 2006b: $85,86)$. Tal proceso representa, para el autor, el mismo paso que va del politeísmo al monoteísmo. La producción masiva de dioses — realizada por la máquina sacrificial arcaica y su traducción mítica - es desmontada por una sola figura, la del Dios monoteísta.

El proceso de desmitificación subvierte varias claves del sistema sacrificial, pero aquí solo recuperaremos algunas. Mientras que en los mitos -y en las prácticas rituales arcaicas - la existencia del chivo expiatorio debe ser inferida, en los Evangelios es explícita. No resulta fortuito, por ejemplo, que en el episodio de La Pasión ${ }^{8}$ se reproduzca el mismo orden de eventos que en los mitos y en los relatos antiguos. Ambos dan cuenta de asesinatos fundadores: a una crisis comunitaria le sucede una persecución, la elección de una víctima y su inminente ejecución. Sin embargo, las conclusiones en ambos son distintas.

Dios envía al mundo a su propio hijo — Cristo - como la víctima precisa para detonar, desde dentro, la maquinaria sacrificial. Cristo advierte su destino y, aun así, se entrega al camino que lo conducirá a la muerte, dado que

6 El proceso de revelación inicia en el Antiguo Testamento, pero es en los evangelios donde pueden observarse, de manera más nítida, cada una de sus fases.

7 Al desmontar el mecanismo que sostenía el orden antiguo, el cristianismo inaugura esta nueva fase de la historia.

8 Para Girard, en estos textos se realiza la mayor desmitificación del mecanismo; en ellos se concreta la unión entre el saber teológico y el saber antropológico que se iniciara desde el Antiguo Testamento. La Pasión constituye la clave más valiosa para comprender el largo proceso victimario. 
su existencia encierra un propósito revelador. La multitud experimenta el contagio mimético que determinará su sacrificio. ${ }^{9} \mathrm{Ni}$ siquiera sus discípulos pueden resistirse al momento de la crucifixión — quienes no lo traicionaron o negaron repetidamente, como Pedro, huyeron o permanecieron pasivos-. Pero, tras su muerte, tal unanimidad es desacreditada.

Los discípulos de Jesús recobran la fe y perpetúan el recuerdo del acontecimiento - la injusticia de su persecución-. La presencia de esta minoría disidente y contestataria — primera minoría cristiana — también se hace explícita. Este desplazamiento de la comunión a la división de la comunidad es lo que permite que la revelación evangélica sea posible.

Asimismo, en otra clave del proceso, la inconsciencia de los perseguidores es denunciada con una frase central del relato: "Padre, perdónalos, porque no saben lo que hacen” (Lc 23: 34 Nuevo Testamento Edición Pastoral). Un planteamiento absolutamente reconciliador, ${ }^{10}$ con el que -lejos de dirigir amenazas a sus sacrificantes - la víctima demuestra su bondad y su singularidad. La víctima es quien clama a Dios para que redima a sus perseguidores.

Resulta crucial advertir que, al renunciar al principio de la reciprocidad mimética — de pagar violencia con violencia-, Jesús coloca la culpabilidad sobre las cabezas humanas. Por eso, Girard sentencia que es ahí donde, por primera vez en la historia, lo divino y la violencia colectiva se separan de manera nítida. La víctima es quien invita a la dimisión total de la violencia: "Habéis oído que se dijo: ojo por ojo y diente por diente. Pues yo os digo que no resistáis al mal; antes bien, al que te abofetee en la mejilla derecha preséntale también la otra; al que quiera pleitear contigo para quitarte la túnica, déjale también el manto" (Mt 5: 38-40 Nuevo Testamento Edición Pastoral).

9 En El misterio de nuestro mundo, Girard consideraba atinado que en los Evangelios nunca se designe a la crucifixión con el mote de sacrificio, expiación o sustitución. Consideraba, en aquel entonces, que con esta reserva se pretendía evitar la confusión entre las finalidades de ambos; equívoco que desafortunadamente terminó generando la "cristiandad". Sin embargo, 30 años más tarde —en Aquel que llega por el escándalo (2006c) - , piensa que utilizar la palabra sacrificio para referirse a ambos casos resulta algo necesario para comprender la unidad paradójica de lo religioso en toda la historia humana. Eso sí, cuidándose de no interpretar eso como un signo de continuidad.

10 De acuerdo con la teoría girardiana, el texto cristiano busca una reconciliación fundada en el perdón que sustituya el papel fundador tenido por la violencia en las religiones arcaicas. Cristo no se convierte en un dios vengador que demanda más víctimas, sino en uno que clama por la justicia y el amor entre los hombres. 
Al humanizar la figura de Cristo, se derrumba esa sacralización de la violencia que envolvía al chivo expiatorio. La Resurrección, contrariamente a los que la identifican como la última fase de la divinización mítica, ${ }^{11}$ es la gran prueba de inocencia. Mientras las deificaciones míticas exhiben un ciclo mimético completo - que va de la demonización a la adoración multitudinaria-, detrás de la divinidad de Cristo no hay satanización unánime ni posterior unanimidad reivindicadora. Solo una pequeña minoría proclama su inocencia y atestigua su divinidad sin necesidad de comprobarla — desde que lo reconocen como hijo de Dios-.

Dicho en palabras de Girard: "ya no son los hombres los que forjan a los dioses; es Dios quien vino a tomar el lugar de la víctima [...] la víctima es divina antes de ser sacralizada" (Girard 2010: 160). Esta diferencia deja abierto un solo camino: detrás de la muerte de Cristo no hay ningún Dios, pues es Dios mismo quien se hace víctima en Cristo. Detrás de la muerte de Cristo solo están los actos de los hombres. Así que, lejos de operar un nuevo escamoteo, la resurrección expone a la violencia humana como eso que había permanecido oculto desde la fundación del mundo.

Con su entrega absoluta, Cristo exhibe la inocencia de todos los chivos expiatorios de la historia, así como la mentira multitudinaria que rodeó su sacrificio. Las víctimas son rehabilitadas por primera vez en la historia. "A partir de ahora ya no podemos aparentar que no sabemos que el orden social está construido sobre la piel de víctimas inocentes" (Girard y Vattimo 2011: 39). $\mathrm{Al}$ interrumpir la marcha del proceso victimario, el saber bíblico lo vuelve ineficaz.

No obstante, y según la propia teoría mimética, aunque la revelación cristiana quitó a los hombres su protección sacrificial basada en el engaño, no ha logrado desaparecer los procesos victimarios y, por el contrario, parece que estos se han ido incrementando.

Precisamente, con el ánimo de acentuar esta paradoja, el autor utiliza el término protección para dejar en claro que el desconocimiento que sostenía el mecanismo sacrificial en las sociedades arcaicas también hacía las veces de

11 Entre los que puede mencionarse al etnólogo James Frazer, quien vio en el cristianismo una última victoria de esta serie de supersticiones (cf. Girard 2002a: 161162), o el filósofo inglés Alfred North Whitehead, quien lamentaba la inexistencia de diferencias claras entre ellos. E incluso, el teólogo protestante Rudolf Bultmann, que prácticamente consideraba el relato evangélico el mito más imponente ( $c f$. Girard 2002b: 11). 
su salvaguarda: "ventilando el secreto de la representación persecutoria, se impide, a la larga, que funcione el mecanismo victimario y que se engendre, en el paroxismo del desorden mimético, un nuevo orden de la expulsión ritual susceptible de sustituir el que se ha descompuesto" (Girard 2002a: 249). No quedando otro exutorio para la violencia humana, esta se liberó generando nuevas crisis.

La paradoja central es que, a medida que la revelación expuso la verdad de la violencia mimética, creció más el rechazo a reconocer la violencia de cada uno. Girard afirma que no estábamos preparados para aceptar la invitación cristiana a dimitir de la violencia. Los hombres deciden, diariamente, desdeñar lo revelado y apegarse a sus falsas diferencias. Hoy atestiguamos que la violencia escala hasta los extremos, pese a que su único fin posible es la autodestrucción absoluta.

Pero el fracaso de la revelación no es un asunto que deba tomarnos por sorpresa. Por el contrario, los textos apocalípticos son, según la tesis mimética, la conciencia de este revés. "El cristianismo es la única religión que habrá previsto su propio fracaso" (Girard 2010: 10). Confrontó a los hombres con su violencia a sabiendas de la catástrofe que eso desencadenaría. Más aún, ese fue uno de sus propósitos.

Cuando Jesús sentencia "no he venido a traer la paz, sino la guerra", anuncia el comienzo de esa crisis. De ahí que Girard considere que los primeros signos del apocalipsis deben rastrearse en la etapa posterior al acontecimiento cristiano pues, desde ese momento, la historia de la humanidad se inscribió en una temporalidad lineal. Distinta a la circularidad que evocaba el sistema mítico-sacrificial - que aseguraba el eterno retorno de los dioses-.

Sin embargo, es importante aclarar que aquella advertencia de Cristo nada tiene que ver con el Dios violento presentado en los textos veterotestamentarios. "Por el contrario, se nos habla de un Dios extraño a toda violencia" (Girard 1982: 214). Si trae la guerra es porque viene a poner al descubierto el conflicto mimético que invade a la humanidad, porque viene a refutar la paz construida sobre la espalda de víctimas inocentes.

En este sentido, afirmamos que la lectura apocalíptica de René Girard exhibe un núcleo absolutamente antropológico. Y la llave para acceder a él debe buscarse, de modo puntual, en la desarticulación religiosa efectuada por el cristianismo hace más de dos mil años.

Revisados en clave girardiana, los textos apocalípticos rompen con la tendencia histórica e inconsciente de responsabilizar a la divinidad de las cala- 
midades acontecidas. "Lo esencial de la violencia apocalíptica predicada por los evangelios no es divina. Esta violencia se atribuye siempre a los hombres, pero no a Dios" (Girard 1982: 217). La violencia del fin de los tiempos, en esta lectura, proviene de la humanidad y nada más. Para ser más exactos, en ella no hay Dios en absoluto.

Esta ausencia pone sobre la mesa otro elemento para entender la interpretación que nos ocupa: la responsabilidad absoluta del hombre en la historia. Tras vincular el horror apocalíptico con los terrores humanos, Girard plantea la responsabilidad como eso que definirá el destino de cada uno.

Es cierto que el deseo siempre es mimético, pero algunos hombres resisten al deseo. Y en eso reside justamente el interés de ser cristiano. [...] no significa que el individuo esté atado de pies y manos frente al deseo mimético. El propio Jesús resistió a él. Hablar de libertad es plantear la posibilidad, que tiene el ser humano, de resistirse al mecanismo mimético (Girard 2006b: 107).

La revelación cristiana convirtió a los hombres en dueños de su destino. La desarticulación de su protección sacrificial solo dejaría lugar para la toma de decisiones consciente frente al desbordamiento de la violencia.

A propósito de ello, Girard recupera la palabra apocalipsis en su doble significado: "como revelación y como despliegue de la violencia" (Girard y Vattimo 2011: 20). Como revelación, el apocalipsis puede conducir al hombre a "la salvación de la paz de Dios" o al encuentro trágico con su violencia. Ambas vías son igualmente posibles; optar por una u otra dependerá de la postura que se asuma frente a lo revelado.

Como despliegue, la marcha apocalíptica acrecienta el saber sobre nuestra violencia. Mientras más se entiende el proceso victimario que sustenta la cultura humana, más se constata su materialización en la catástrofe actual. "El cepo (leverrou) del asesinato fundador, desmontado por la Pasión, libera hoy una violencia planetaria, sin que podamos volver a cerrar lo que se abrió" (Girard 2010: 11).

Paradójicamente, el mensaje evangélico ha comenzado a comprenderse cuando la escalada a los extremos es la única realidad. Por incomprensible que esto parezca, para Girard es lo que determina que el apocalipsis funde una esperanza.

Quien repentinamente ve la realidad no está en la desesperanza absoluta de lo impensado moderno, sino que recupera un mundo en que las cosas tienen un senti- 
do. La esperanza solo es posible si nos atrevemos a pensar los riesgos del momento actual. A condición de oponerse al mismo tiempo a los nihilistas, para quienes todo no es más que lenguaje, y a los "realistas", quienes niegan a la inteligencia la capacidad de palpar la realidad: los gobernantes, los banqueros, los militares que pretenden salvarnos, mientras día a día nos hunden un poco más en la devastación (Girard 2010: 14).

La esperanza radica, pues, en advertir la catástrofe y en reconocer nuestra responsabilidad en ella. Pero, sobre todo, radica en anunciar la llegada de un reino que no es de este mundo ni es para todos, ${ }^{12}$ de un reino que exige la renuncia incondicional a la reciprocidad violenta.

Este tipo de esperanza no comparte la confianza en una reconciliación gestada por la razón humana, pero tampoco en una impulsada por una moral natural entre los hombres. La paz no es asumida como ese fin teleológico que buena parte de la filosofía postularía. Puede decirse, en este sentido, que la lectura girardiana abreva mucho más de Clausewitz que de Hegel o de Kant.

Si bien en El misterio de nuestro mundo (1982), Girard creía que el saber universal de la violencia podía producir la reconciliación universal, 30 años más tarde lo rechaza. Una vez que el mundo ha perdido su protección sacrificial, considera, solo puede constatar la multiplicación de los conflictos.

Esa escalada a los extremos que Clausewitz observa es lo único que impele a la urgencia de renunciar a la violencia. Ciertamente el tiempo apocalíptico anuncia la reconciliación, pero no como su consecuencia, sino como su revés. El fin de los tiempos y el retorno de Dios corresponden a un mismo destino: en el corazón del conflicto está, también, el acceso al reino de Dios. ${ }^{13}$ Catástrofe y esperanza aparecen, entonces, como las dos caras de la misma moneda.

12 A decir de Girard, solo algunos serán capaces de reconocer la catástrofe y de comprender su responsabilidad en ella. Afirma - no sin antes rechazar un apologista de la conversión- que, únicamente, aquellos capaces de seguir el llamado cristiano pueden percibir la destrucción que se encuentra en proceso entender que detrás de ella no hay un padre terrible, sino la desnudez de nuestros actos (Chaintre y Ortoli 2009).

13 Para Girard, la apocalíptica cristiana no representa, precisamente, una revelación terrorífica, pues lo verdaderamente aterrador sería la total ausencia de sentido. Por el contrario, sostiene que el Apocalipsis "es reconfortante", porque satisface el deseo de significación. En pocas palabras, porque logra otorgar sentido a lo que había permanecido tergiversado por las lecturas míticas de la violencia (Mendoza 2008). 
Aunque, a decir del autor, el fracaso de la revelación ya ha dejado claro que esa reconciliación no tuvo ni tendrá lugar en este mundo. "El triunfo de Cristo solo tendrá lugar en un más allá, cuyo espacio y tiempo no podemos definir" (Girard 2010: 85). En este aspecto, la esperanza girardiana nos recuerda el aforismo kafkiano, según el cual existe la salvación, pero no para nosotros. Sin embargo, que el devenir del mundo escape a nuestro control no implica que no se deba reflexionar y actuar sobre su acontecer.

La importancia de la perspectiva escatológica consiste, precisamente, en otorgarle un sentido a la historia; en invitar a imitar a Cristo, en vez de negarse a ver la violencia que rige las relaciones humanas. Y esto a pesar de reconocer que la escalada a los extremos es la única ley que impera en nuestra era. "Hay que luchar hasta el final, aunque uno piense que ese es un vano intento" (Girard 2010: 120).

$\mathrm{Al}$ vincular violencia y revelación, el tema apocalíptico convoca a la responsabilidad humana; es decir, a la toma de una postura ética frente al fin de los tiempos: creer en la violencia o no creer más en ella. Nuestras conductas miméticas deben transformarse en actos responsables. Aunque la armonía universal es irrealizable, cada uno debe esforzarse en reconocer su similitud con el Otro.

En este sentido, y desde nuestra perspectiva, la tesis girardiana plantea al apocalipsis como un espacio metapolítico, en tanto que sugiere un camino para superar la reciprocidad violenta que define a la política: la conversión. "Solo una imitación positiva nos pondría a justa distancia de lo divino. La imitación de Cristo es esa cercanía que nos pone a distancia. A quien debemos imitar no es al Padre, sino a su Hijo..." (Girard 2010: 181). Únicamente en la imitación puede encontrarse la salvación de algunos.

Esto facilitaría pasar de la imitación a la identificación con el otro, "restableciendo una distancia en el seno mismo del mimetismo" (Girard 2010: 163). Poniendo a distancia al padre, dándole un rostro, los hombres pueden convertirse en hermanos "en" Cristo. Así, al relacionarse con el otro desde el "como a ti mismo" expresará la materialización del llamado cristiano.

Imitar a Cristo es identificarse con el otro, borrarse ante él: 'De cierto os digo que cuanto hicisteis a uno de estos hermanos pequeños míos a mí me lo hicisteis'. La identificación supone una aptitud singular para la empatía. De allí surge el recuerdo constante, en los textos apocalípticos, del riesgo que constituyen los Anticristos, del peligro que cada vez más constituirán. En efecto, solo Cristo nos permite rehuir la imitación de los hombres (Girard 2010: 199). 
La imitación de Cristo es lo único que permite salir de la espiral mimética: recobrar una distancia con el otro para ya no imitarlo, ni ser imitado por él. Visto en estos términos, la única posibilidad de redención exige la disolución del sujeto, de su clausura metafísica, en tanto ideal de autonomía y de diferencia.

Quizá no haya otro momento más idóneo para aceptar el llamado de Cristo a la no-violencia que este, en el que la destrucción total se ha vuelto absolutamente perceptible. La teoría mimética insiste en atribuir al individuo la responsabilidad de los sucesos por venir, pues sostiene que ni la lectura fundamentalista ni la progresista logran entender que el apocalipsis no es ninguna metáfora.

Entre los grandes triunfos de la revelación cristiana puede contarse que "el horizonte ideológico de la cultura contemporánea esté construido por completo en torno a la centralidad de las víctimas, las víctimas del Shoa, las víctimas del capitalismo, las víctimas de las injusticias sociales, de las guerras, de las persecuciones políticas, del desastre ecológico, de las discriminaciones raciales, sexuales, religiosas" (Girard y Vattimo 2011: 15). Y, sin embargo, es preciso advertir que, en la mayoría de los casos, no se trata más que de simples marcos discursivos o de nuevas estructuras de contención - katechonque pretenden retardar el acontecimiento apocalíptico.

Hoy más que nunca, la violencia se ha diseminado en las relaciones humanas confirmando, con Heráclito, que es ella — polemos - padre y rey de todo. Fuera y dentro de las sociedades, las causas materiales e ideológicas del disenso y de la oposición se han multiplicado. Ha alcanzado tal extremo que puede observarse en aquello que los textos apocalípticos anunciaban: "una confusión entre los desastres causados por la naturaleza y los desastres causados por los hombres" (Girard 2010: 11). El sinsentido que nos rodea devela la precariedad de cada orden que intentamos fundar.

Tal escenario nos obliga a encarar nuestra violencia como nunca. "Somos la primera sociedad que llega a saber que puede destruirse de manera absoluta" (Girard 2010: 14). La tarea de la revelación se mantiene inconclusa. Y probablemente la mejor oportunidad para asumir nuestra responsabilidad se encuentre en esta época en la que, como en su momento afirmó Simone Weil, todo parece perdido.

El sujeto mesiánico no contempla el mundo como si estuviera salvado. Más bien - en palabras de Walter Benjamin - contempla la salvación solo mientras se pierde en lo insalvable. Así de complicada es la experiencia de la 
klesis, así de difícil es permanecer en la llamada (Agamben 2006: 49). Evocando a Benjamin, solo la esperanza desesperanzada podría hacer estallar, de una vez por todas, el motor sacrificial de la historia.

\section{Bibliografía}

Agamben, Giorgio (2006). El tiempo que resta: Comentario a la carta a los romanos. Madrid, Trotta.

Chaintre, Benoit, y Steven Ortoli (2009). "René Girard: 'El apocalipsis no es una metáfora’ (entrevista)”, Philosophie Magazine, en: <http://www.alcoberro.info/ pdf/girard4.pdf>, consultado por última vez el 10 de abril de 2019.

Clastres, Pierre (1987). Investigaciones en antropología política. México, Gedisa.

Clausewitz, Carl von (2015). De la guerra. México, Colofón.

Freud, Sigmund (1986). Tótem y tabú. México, Alianza Editorial.

GIRARD, René (1982). El misterio de nuestro mundo. Claves para una interpretación antropológica. Diálogos con J. M. Oughourlian y G. Lefort. Salamanca, Ediciones Sígueme.

GIRARD, René (1989). La ruta antigua de los hombres perversos. Barcelona, Anagrama. GIRARD, René (2002a). El chivo expiatorio. Barcelona, Anagrama.

GIRARD, René (2002b). Veo a Satán caer como el relámpago. Barcelona, Anagrama.

GIRARD, René (2005). La violencia y lo sagrado. Barcelona, Anagrama.

GIRARD, René (2006a). Literatura, mímesis y antropología. Barcelona, Gedisa.

Girard, René (2006b). Los orígenes de la cultura. Conversaciones con Pierpaolo Antonello y João Cezar de Castro Rocha. Madrid, Trotta.

GirARD, René (2006c). Aquel que llega por el escándalo. Madrid, Caparrós Editores.

Girard, René (2010). Clausewitz en los extremos. Política, guerra y apocalipsis. Conversaciones con Benoît Chantre. Madrid, Katz.

Girard, René, y Gianno VATtimo (2011). ¿Verdad o fe débil? Diálogo sobre cristianismo y relativismo. Barcelona, Paidós.

GIRARD, René (2012). El sacrificio. Madrid, Editorial Encuentro.

MendozA, Carlos (20o8). "Pensar la esperanza como apocalipsis. Conversación con René Girard”. Letras Libres, en: <http://www.alcoberro.info/pdf/girard3.pdf>, consultado por última vez el 12 de abril de 2018.

Nuevo Testamento Edición Pastoral (1972). Hurault, Bernard (ed.). Madrid, Sociedad Biblioteca Católica Universal/Editorial Verbo Divino.

Schmitт, Carl (2014). El concepto de lo político. Madrid, Alianza Editorial.

Traverso, Enzo (2015). "Introducción", en El significado de la Segunda Guerra Mundial. Madrid, Colección Viento del Sur.

\section{Anabel Muñoz Trejo}

Licenciada en Ciencias Políticas y Administración Pública por la Facultad de Ciencias Políticas y Sociales, UnAM. Maestra y doctora en Filosofía Política por 
la Facultad de Filosofía y Letras, UNAM. Ha participado como ponente en distintos congresos nacionales e internacionales. Ha colaborado como consultora externa para “OXfam México, A. C.”. Se ha desempeñado como tallerista en el “17 Instituto de Estudios Críticos”, así como para distintas entidades partidistas. Ha sido profesora asistente para diversas asignaturas en la Facultad de Ciencias Políticas y Sociales, UNAM; profesora titular en el Instituto Marillac I. A. P. y en la Universidad Autónoma de la Ciudad de México. Ha publicado los artículos: “Deseo, identidad y violencia en la obra de René Girard”, en $L a$ finalidad de la Filosofía, UNAM, 2014; "Deseo mimético e identidad: pensar a la violencia en el mundo actual”, en la Revista Sincronía, Universidad de Guadalajara, 2017; "La violencia sacrificial como fundamento del orden a través de la teoría mimética”, Revista Antrópica, Universidad Autónoma de Yucatán, 2018. Ha colaborado como dictaminadora de productos académicos de investigación para el Departamento de Filosofía de la Universidad Iberoamericana. 